\title{
Healthcare students as innovative partners in the development of future healthcare services: An action research approach
}

\section{Abstract \\ Background}

Health care systems in Norway and the western world have experienced extensive changes due to patients living longer with complex conditions that require coordinated care. A Norwegian healthcare reform has led to significant restructuring in service delivery as a devolution of services to municipalities.

\section{Action research design}

Partners from three rural healthcare services, students from four professional programs, and one lecturer from each of the professional programmes used a collaborative approach to obtain new knowledge through interprofessional practice. Using an action research design, the research group facilitated democratic processes through dialogues with healthcare services and students. The design is visualised as a cyclical process in which each cycle contributes to improvements, innovations, and increased understanding. A total of 32 students and 3 supervisors were interviewed before and after the clinical practice experiences. Fieldwork was conducted during three clinical periods.

\section{Findings}

Interprofessional student groups formed small healthcare teams and assessed patients with chronic and long-term conditions. Students prepared and negotiated patient follow-up. The teams' responsibilities led to reflective practices that enhanced their professional knowledge. The teams achieved a new understanding of patient situations, which influenced "second opinions" for patients with complex conditions and led to innovative practices. The change in perception of patient needs led to a changed professional approach. The students' perceptions changed as they learned from and about each other and in collaboration with the health service; this led to more coordinated care of patients with complex conditions. Interprofessional learning in community settings provided a platform to improve both healthcare education and rural healthcare services

\section{Conclusion}

This research contributes to knowledge of how students' placement in interprofessional teams can enhance students learning from, with and about each other. The student teams promoted new ways of approaching and delivering complex patient treatment and care in community 
healthcare service. Collaborative partnerships in interprofessional learning have potential in the wider international arena as a means for practice improvement.

\section{Highlights}

- Improved quality in rural healthcare services

- Cooperation between healthcare services and healthcare education contributes to new innovative learning practices

- New interprofessional learning practices have the potential to change the focus from specialist healthcare to community healthcare through an integrated interprofessional learning approach

Key words: Interprofessional learning, community healthcare, innovative practice, practicebased learning, action research 


\section{INTRODUCTION}

Interprofessional practice is viewed as a means to improve health services for people with long-term and complex conditions who are in need of coordinated care (Reeves et al., 2010). Learning of collaboration across professional boundaries has mainly been studied in specialized hospital wards rather than in community settings, and there is a need for empirical exploration of the relationships between IPE, teamwork and collaborative practice (Thistlethwaite 2012). In this research study, the focus is on the mutual learning that occurred in the community healthcare service and within the student groups during a module of interprofessional education (IPE) in a northern university of Norway. IPE is defined by CAIPE (2002) as occasions when two or more professions learn from, with and about each other to improve collaboration and the quality of care. The learning that arises from interaction between members (or students) of two of more professions (Freeth et al., 2005) can be a result of IPE or occur spontaneously. This article focus on the learning that occurred due to a collaborative approach by four health professional programs: medicine, nursing, physiotherapy and occupational therapy (OT) and healthcare services. Reeves et al., (2008) stated that there is a need for more research on the impact of IPE on professional practice.

This study will explore how partnerships for the contextualisation of learning environments in community health services can contribute to the knowledge and requirements of new methods of working. Thistlethwaite (2012) and Barr et al., (2014) recommend that educators and practicing healthcare professionals collaborate to provide authentic learning experiences for students. This article will also present unintentional outcomes of interprofessional learning when student teams worked with patients selected by healthcare services.

\section{Background}

Public healthcare systems in Norway, as in much of the Western world, are encountering profound challenges in the organisation and delivery of efficient and effective services. Demographic changes, increases in the number of people living with chronic diseases, and advances in medical expertise mean that more people are surviving lifethreatening conditions. The need for health care services will increase; however, the recruitment of qualified health care professionals has been limited.

The Norwegian government implemented The Coordination Reform (Norwegian Ministry of Health and Care Services, 2012) to address these changing demands. Within this document, municipalities are perceived as key agencies for new modes of organising and working across 
traditional boundaries. However, the success of this transformation will depend on the development of new relational and cooperative competencies and modes of working.

The need to develop new competencies and modes of working is addressed in the Norwegian white paper Education for Welfare (Norwegian Ministry of Education and Research, 2012) and in recent research in healthcare education (Benner et al., 2010; Frenk et al., 2010; Solvoll and Heggen, 2010; Thistlethwaite, 2012). The main arguments in both domains are that societal changes and reforms in health and welfare services require corresponding changes in health and social education, particularly through clinical learning environments. However, clinical placements must be developed in cooperation between healthcare education and healthcare services. This cooperation will ensure that students develop the competence, skills, and knowledge relevant to future health care work.

Interprofessional learning (IPL) is being utilised worldwide as a means to assist fragmented healthcare systems and address unmet needs (Hopkins et al., 2010). A review of IPL (Reeves et al., 2010) indicates that the learning outcomes, to an extent, improved how professionals worked together. The students' understandings of the roles of other team members were enhanced, and students and supervisors perceived the programme to be valuable for student learning. The Thistlethwaite review of IPE (2012) shows positive interaction among different professions in connection with authentic learning experiences for students.

To investigate some of these challenges, an IPE programme was conducted from 2013 - 2015 with a collaborative approach that included three rural health services and four graduate health professional programmes at a university in a northern region of Norway. The aims of the project were:

1) To establish interprofessional learning environments for health care students in community health care services.

2) To describe, analyse, and disseminate experience and knowledge from the new learning environments.

Students from medicine, nursing, physiotherapy, and occupational therapy (OT) programmes formed interprofessional teams during the two weeks of clinical placements. The research questions were as follows: How do students perform interprofessional cooperation in clinical practice? What impact does an interprofessional student group have on municipal health 
services? Frenk et al. (2010) states that there is a need to promote interprofessional education that enhances collaborative and non- hierarchical relationships in teams. The current study contributes to the body of knowledge in this area including knowledge of how students themselves can establish teams bearing impact for future healthcare service.

\section{ACTION RESEARCH}

To address and acknowledge aspects of collaboration and the processes involved, we used an overall action research approach that is suited to improving the different practices involved in the research (Elliot, 1991; Kemmis and McTaggart, 2000; McNiff and Whitehead, 2011).

\section{Design}

An action research design inspired by Elliot (1991) was used to visualise the action research process. This design should contribute to understanding, the negotiation of understanding, and the creation of new knowledge. As the action research process is cyclical, improvements in and amendments to the practice should be made with each cycle (Elliot, 1991). The research process in each cycle should explore the interventions and lead to an amended and improved plan. The action research cycles were as follows:

- Cycle 1 focused on preparing to place interprofessional student groups in clinical practice. The preparation was conducted in accordance with each professional programme and aimed to prepare mentors and healthcare settings.

- Cycle 2 focused on how the students learned with, from and about each other as defined by (CAIPE, 2002).

- Cycle 3 focused on three different perspectives of interprofessional learning: those of the students, the mentors, and the health service personnel.

Stakeholders at the university and in healthcare services were involved in designing the research to secure leadership commitment at all levels (Reeves et al., 2012). Students were recruited through informational bulletins and meetings and could withdraw from the project at any time. A total of 32 students from medicine, nursing, physiotherapy and OT were included and formed 9 different interprofessional groups. Each team consisted of one student from each of the professional programmes and was subjected to two weeks of clinical placement in rural health services. The students were performing the last part of their graduate professional programme and were responsible for two to three patients with long-term and complex 
conditions because this presented a challenge according to the Coordination Reform (2012). The students negotiated how they could work as a team as they assessed the patients' needs, suggested and initiated different coordinated initiatives, and explored how they learn with, from and about each other (CAIPE 2002). Everyday healthcare practice was the basis for their IPL activities. In daily group meetings and based on their meetings with their patients, they negotiated alternative treatment and care plans and decided which initiatives they could implement during practical work with the patients. After two weeks of IPL placement, each group reported their results and suggestions for future treatment and care plans to the health services included.

Data were collected from multiple sources to monitor changes over time (McNiff and Whitehead, 2011). Semi-structured qualitative interviews were conducted individually with all students and their supervisors before clinical placement to determine a baseline. All interviews were transcribed verbatim. Recordings from IPL team meetings and supervising sessions were part of the fieldwork conducted in one community health service and were supported by field notes. Inspired by McNiff and Whitehead (2011), circulated minutes, reflection logs and recordings of workshops and dialogs throughout the process were part of these data.

Transcribed material from interviews, circulated minutes and field notes were analysed during monthly meetings as an inquiry of both practical issues and topics of mutual concern.

Validation was both an internal and an external process. After each cycle, based on student interviews and dialogues with the health services, the project group explored practical knowledge and extracted explanations of new knowledge. Preliminary findings were discussed and explored with the supervisors as part of the internal validation and presented to the students for member checking (Cho and Trent, 2006). An external panel of participants interested in IPE functioned as critical friends in open seminars. During these seminars, students, researchers and health personnel presented their perspectives and engaged in dialogues concerning their understanding. This validation process mirrored and adjusted the researchers understanding of the new knowledge extracted. Misunderstandings and/or new aspects of student learning were reflected on and contributed to an expanded understanding. Although the students could not observe their effects on the performance of health professionals and how their thinking could change practices, they could appreciate that interprofessional collaboration affected the existing practices as they questioned current practices and suggested new strategies. 


\section{Ethical considerations}

In July 2013, the Norwegian Social Science Data Services (NSD) approved the study with approval number 34895. The Faculty of Health Sciences at UiT the Arctic University of Norway allowed the study to occur by allowing student participation in clinical placements for interprofessional learning purposes. The project was approved by the Regional Ethical Committees for Medical and Health Research Ethics in September 2014 and allowed researchers to participate in the field at locations where patient care and treatments were provided. The additional approval expanded the data to include fieldwork in Cycles 2 and 3 of the project.

Students, health personnel, and lecturers from the professional programmes involved in the project were informed of the study's purpose in an explanatory letter and were provided with a written consent to participate. The students volunteered to attend interprofessional placements and participate in interviews before, during, and after placement. The researcher in this article was also a lecturer in the nursing programme. It was important to maintain a separation of these roles in interviews with the students and during fieldwork because the students were prone to seeing the researchers as teachers and requesting advice.

\section{FINDINGS AND REFLECTIONS}

In the following section, the article will describe and discuss how the students worked as interprofessional teams and how this influenced health care practices. The situations that students participated in during their two weeks of clinical placements are typical IPL situations to learn with, from and about each other to improve collaboration (CAIPE 2002).

\section{Preparing the collaboration}

The interprofessional student group initiated the collaboration by introducing themselves to the other students. The presentations focused on what practical experiences they had participated in earlier in their studies. None of the students had worked with students from other programmes during any clinical practice period, and they expressed that this was a new experience for them. Expectations for the clinical placements included becoming more acquainted with the other professions. The nursing, physiotherapy, and medical students all 
expressed a desire to know more about occupational therapy. The students had heard of the profession but had minimal knowledge of what an occupational therapist did or what the profession was. The OT student said that she hoped her perspectives would be heard because she realised that her knowledge was unknown to the others. A medical student anticipated cooperating with other students, stating that: "This is my chance to work closely with others. Most of the time I work by myself in my GP practice, and I have never worked with students from your profession.” The student anticipated a new experience in this group.

All the students expressed positive attitudes and expectations regarding the forthcoming cooperative work. The students also had expectations for themselves. A nursing student said, "I hope I will get a clearer idea of my role as a nurse. This is still a bit vague for me."

This open introduction with the students introducing themselves to the others was important to establishing a team and a shared team identity, as referenced by Reeves et al. (2010). It involved becoming acquainted with the other participants and bridging knowledge as the group shared practical experiences and were open with each other. The initial meeting was to learn about the others, not only as professionals but also as partners with whom they wanted to cooperate. However, one nursing student was open to the need to explore her own identity. Clinical placements are essential for shaping identity (Arreciado Marañón and Isla Pera 2015) and working with other professions, and reflection upon her own professional approach relative to other professions was possible. The positive atmosphere provided a platform for further work and initiated teamwork. As a core competency for collaborative practice (Interprofessional Education Collaborative Expert Panel 2011), assembling the team is a central element. The students had never worked closely with other professions or explored how they could cooperate as a team: "How many of us should meet with the patient? Will this be overwhelming?” The students discussed how they should conduct their first meetings with patients. The students approached the ethical issue of overwhelming the patient by having an excessive number of professionals at one meeting and negotiated how they wanted to work together.

The IPL teams also discussed how they could map the patients' statuses. The teams used a standardised mapping tool and divided responsibilities during the meeting. The OT student commented on the one-sided focus of the mapping tool: "This tool is focusing only on the problems for the patients. We must remember to see the patients ` possibilities. I will make a new suggestion.” Initially, the groups discussed how they could best use each other's 
professional competences. The groups needed to structure the collaborative efforts and decided to meet early each day, determine who should work together, and then meet at the end of each workday: "This is how we can keep each other up to date and plan what we do next."

By not taking pre-existing modes of working for granted, the students listened to each other's expectations and discussed how they wanted to work together.

\section{Exchanging ideas leads to enhanced understanding}

The community health services selected patients with chronic and long-term conditions available for the student group. During the two-week placements, the students worked in different combinations depending on their tasks: all four professions combined, in pairs, and individually. The teams initiated their collaboration by receiving a collective oral report from a healthcare worker who knew the patients. The teams continued by reading the patients' records. The medical student took notes from the medical records at the General practitioners' office. The nursing, physiotherapy, and OT students read the patients' records at the nurses' station.

The teams met to share what they had found in the written records, what other relevant information they needed, and how they understood the patient records. Listening to what information the other students needed led to an exchange of ideas. In these dialogues, different aspects of professional knowledge appeared. "I did not know that nurses knew so much about nutrition," said the physiotherapy student, who expressed appreciation for the nursing student's contribution to their mapping. This type of knowledge, which was unknown to the other professions, represented a discovery of a new understanding, in this case, of the nurses’ responsibility and knowledge regarding nutrition and malnutrition. This insight contributed to an expanded understanding of the complex conditions of the patients. Students shared their professional knowledge and opinions after meeting with the patients. Sharing knowledge with the other students contributed to learning with each other. Because a single professional approach is not sufficient to meet the needs of complex and long-term health problems (Reeves et al. 2010), the students valued the different opinions of team members because they provided new understanding of the situation. 


\section{Sharing responsibility}

Different professional approaches, different understandings, and different preunderstandings were explored during the team meetings. The shared context of being together with the patients provided the opportunity to develop new understandings. A physiotherapy student reflected: "I told my team about my different choices of treatments. By hearing my own explanations, I understood what I had to do. I would normally have taken this to my supervisor and asked what I should do, but explaining this to the others made me more certain. The responsibility that we share in a group makes me think more about my own knowledge. It is both the responsibility I have as the only physiotherapy student in the group and our sharing of the responsibility that opens up a different understanding.” The interprofessional student teams were engaged in the patients' follow-up; they expressed that the responsibility they had as a team forced a reflective practice (Schön, 1987) that enhanced their professional knowledge. Being part of the team challenged different perspectives of situations. The teams took responsibility by carrying their own professional thinking into the group, and this changed the professional dialogue.

Initially, the students focused on working together as they developed their pre-understandings of the specific theoretical and practical knowledge that the other professions had. The team occasionally targeted what they wanted to learn. For example, the nursing student asked the physiotherapy student to assist her in mobilising a patient. The nursing student had noticed that the procedure was painful for the patient and wanted the physiotherapy student to assist in finding alternative approaches. In another situation, the OT student wanted to observe the medical student completing a Mini Mental Status (MMS) examination on a patient because she had not yet performed one. The students wanted to learn from each other.

Decisions regarding how to work with the patients were discussed and agreed upon in sequences early each morning and at the end of each workday. Because the students also worked together without targeted pre-understandings of what the other professions could contribute, they discovered new aspects of understanding. After being together when meeting patients for the first time, the teams shared their individual professional understandings with each other. A medical student said: "To see the patient in his own home was completely new for me. Usually the patients come to me with a problem. Here I could listen to what the patient said, and I understood it from a wider perspective. I have more information now than what I could have obtained from the GP office. I also saw how the physiotherapy student 
helped her to the toilet. I saw her moving around in her natural environment, being comfortable, and I could see for myself what she tried to explain.”

Being together with patients provided new insights for students from all four professions. The students also discovered that they gained similar, but different, information from meeting the patients together. Their knowledge was first transformed by a new professional understanding; it was then expanded by observing the views of other professionals. The students shared responsibilities as a group and became aware of each other's contributions. “The best outcome for the patient" occurred when the students cooperated with their expanded knowledge of how each could contribute. Learning with each other occurred when the students shared responsibility for the patients. This integration between work practices (Reeves et al., 2010) became the basis for an enhanced understanding of how the students could share knowledge. This real life experience and shared learning for the students contributed to an extended dimension of understanding of how and what they could learn. The responsibility made the team stronger, as they had to share and trust different professional judgements.

\section{Improved practice}

The reflective student meetings expanded the students understanding of the patients' situations, as their findings were shared with each other and with their supervisors. By being together with the patient as a team, the students expanded their understandings of the patients' situations in a different way than the healthcare personnel had. Students' reflections with the supervisor included the following: "It can look as if the wife has taken control over the husbands' life (by moving her office into their home) and not let him take responsibility for his own situation." "She needs support to leave the house and not be with him all the time”.... "His depression may be affected by receiving too much help. His ability to have a full recovery is also dependent upon on what guidance and help the wife obtains in his rehabilitation process.” The student's supervisor explained that the nurses had encouraged the wife to move her office to her home and had not observed how this had affected the husband's potential for recovery after his stroke.

In another case, the students were given responsibility for a complex patient situation. The health service had cared for the patient for several years. The student group met the patient without a pre-understanding of the treatment and care the patient had previously received. 
Among other ailments, the patient suffered from pain caused by severe spasms. The team examined the patient carefully. After examining and observing his potential, they suggested new initiatives to improve the situation. The students noted the same problem that the healthcare service had noticed but applied new approaches to solve the problem. They suggested a different way of administering his medication, a different approach to supporting the patient in his bed, and an adjustment to his wheelchair. The supervisor encouraged the IPL team to discuss alterations with the health personnel and to attempt to implement the recommendations with the patient's consent.

This collaboration in real-life situations challenged the team to work differently, which was a meaningful activity (Thistlethwaite 2012). The challenges presented by patients were met with integrated, not singular, initiatives that reflected the complexity of the health problems, which was noted as one of the problems with the Coordination Reform (2012) at the community level.

Students' interprofessional practices functioned as a review of the patients' situations and as a “second opinion” for patients with complex, long-term conditions. Communication and cooperation between the IPL team and the rural health services was documented in the patient journals and led to changes in treatment and care, unintentionally becoming an innovative practice.

The students formed teams and discussed how they viewed their responsibilities. They attended to the work differently as they negotiated what would be ethically acceptable; for example, based on the patients' conditions, they determined how they would conduct assessments, what initiatives they could take as a team and what their further recommendations would be for continuous treatment. This new contextualisation of experiences encouraged the students to explore beyond their traditional modes of working.

The interprofessional teamwork also changed the students' views of the other health professionals from stereotypic descriptions to deeper understandings of the other professionals as they learned from and about each other, which was also reflected in the health services provided as the team influenced the health services in an ongoing process. The supervisor observed that the professional approach had room for improvement. The student team had surprised her: "I have seen real interprofessional cooperation for the first time. We have to work to change the way we work, but it will take time. It is challenging. I have seen how the young students have improved treatment and care for the patients in a short time by 
working together.” The dialogues and reflective practices between healthcare services, healthcare students, and healthcare education provided a platform to improve future healthcare education and to begin a process of transformation within the health services. This was welcomed, as the health personnel received a professional review of complex patient situations, albeit unintentionally. The responsibility for fragile and complex patient situations remains challenging, especially for rural health services after the Coordination Reform (2012), and they welcomed the thorough assessment of their patients.

\section{Implications}

As indicated in the findings, students in interprofessional teams challenged how they had learned to perform their professional work within their healthcare education. Assessing and working with the patients in collaboration had opened up new processes of working. These processes relate to national and international policy papers (Coordination Reform, 2012, Hopkins et al., WHO 2010) and have placed a focus on new ways of organising and performing professional work. This research also shows how health services without an established interprofessional approach can be a learning environment for interprofessional student teams, as long as they are open to student learning as part of their own learning. The number of people living longer with complex conditions and requiring coordinated care produces a need for new methods of working. Shorter admission time for specialist health care in hospitals extends the responsibility of professionals in community health services regarding complex and long-term care. The students discovered how they could cooperate both in group discussions and in sharing practical work, which provided insight into new aspects that were relevant for patient treatment and care. In this study, the students` perceptions of other health professionals changed as they cooperated with students from other health professional programmes. The partnership between health services and the university also focused attention on different methods of working. This partnership indicates that IPE can benefit patient treatment, but how this altered the quality of treatment and care has not been studied. This study shows that partnerships for the contextualisation of learning environments, as referred by Thistlethwaite (2010) and Barr (2012) can contribute to innovative practices in which new ways of performing care can be nourished and influence health services that benefit IPE activities. 
The Lancet reported (Frenk et al., 2010) that health care education programmes need to alter curricula to address methods of working according to future demands in health service. This article shows benefits of including interprofessional learning as a new learning environment that benefits student learning and the development of services for patients in community health services. Authentic learning environments in communities can contribute to providing IPL, as this research indicates, both for students and for the health services. Collaborations between universities and health services regarding interprofessional placement have the potential to contribute in the following ways: 1) students from different health professional programmes can experience new modes of working and learn how they can benefit the patients and 2) health services can address complex situations with an interprofessional approach while student teams explore new collaborative ways of working. How the patients experienced the interprofessional approach is an interesting avenue of exploration for future research.

\section{Conclusion}

The IPL student teams contributed to creating an innovative practice in rural healthcare services and have challenged traditional professional ways of thinking and working. This innovative approach can contribute to changes in health care services if collaboration and openness to the participation of students is maintained. The responsibility for complex patient situations enhanced the students' understanding and altered their views of each other's professional knowledge and contributions. The project indicated that enhanced learning is suitable for complex and long-term care, which is a major responsibility of community health services. The students learned from, with and about each other, and it is of interest to investigate whether the students will benefit from their placement as future health care personnel and whether and how the patients are included in coordinated care.

\section{Study limitations}

This project was conducted in rural municipalities in North Norway and is contextspecific. The students volunteered to attend IPE practice, and this might have resulted in recruitment of students particularly open to cooperation with other students. The supervisor from the health service also made an important connection between the student group and the 
health service and encouraged both partners to attempt to utilise these new modes of working. This connection may have influenced the positive outcomes of this project.

\section{References}

Arreciado Marañón, A., Isla Pera, M.P., 2015. Theory and practice in the construction of professional identity in nursing students: a qualitative study. Nurse Education Today 35 (7), 859-863. doi:10.1016/j.nedt.2015.03.014.

Barr, H., Helme, M., D'Avray, L., 2014. Review of Interprofessional Education in the United Kingdom 1997-2013. CAIPE, Fareham.

Benner, P., Sutphen, M., Leonard, V., Day, L., 2010. Educating Nurses: A Call for Radical Transformation. Jossey-Bass, San Francisco, CA.

Carpenter, J., Dickinson, H., 2008. Interprofessional Education and Training. Policy Press, Bristol.

Centre for the Advancement of Interprofessional Education (CAIPE), 2002. Defining IPE. Retrieved September 22, 2015 from: http://caipe.org.uk/resources/defining-ipe/.

Cho, J., Trent, A., 2006. Validity in qualitative research revisited. Qualitative Research 6 (3), 319-340. doi:10.1177/1468794106065006.

Elliot, J., 1991. Action Research for Educational Change. Open University Press, Philadelphia, PA.

Freeth D., Hammick M., Reeves S., Koppel I., Barr H., 2005. Effectice Interprofessional Education: Development, Delivery and Evaluation. Oxford: Blackwell Publishing 2005.

Frenk, J., Chen, L., Bhutta, Z.A., Cohen, J., Crisp, N., Evans, T., Fineberg, H., Garcia, P., Ke, Y., Kelley, P., Kistnasamy, B., Meleis, A., Naylor, D., Pablos-Mendez, A., Reddy, S., Scrimshaw, S., Sepulveda, J., Serwadda, D., Zurayk, H., 2010. Health professionals for a new century: transforming education to strengthen health systems in an interdependent world. Lancet 376 (9756), 1923-1958. doi:10.1016/S01406736(10)61854-5.

Hopkins, D., Burton, A., Hammick, M., Hoffman, S.J., 2010. Framework for Action on Interprofessional Education \& Collaborative Practice. WHO, Geneva.

Kemmis, S., McTaggart, R., 2000. Participatory action research. In: N.K. Denzin, Y.S. Lincoln (Eds), Handbook of Qualitative Research, 2nd ed. Solid Action on Globalization and Environment, Thousand Oaks, CA. 
McNiff, J., Whitehead, J., 2011. All You Need to Know about Action Research, 2nd ed. Solid Action on Globalization and Environment, Thousand Oaks, CA.

Norwegian Ministry of Education and Research, 2012. Education for Welfare (Utdanning for Velferd). Oslo, Norwegian Ministry of Education and Research.

Norwegian Ministry of Health and Care Services, 2012. The Coordination Reform (Samhandlingsreformen), Oslo, Norwegian Ministry of Health and Care Services.

Reeves, S., Lewin, S., Espin, S., Zwarenstein, M., 2010. Interprofessional Teamwork for Health and Social Care. Blackwell Press, Chichester, West Sussex.

Reeves, S., Zwarenstein, M., Goldman, J., Barr, H., Freeth, D., Hammick, M., Koppel, L., 2008. Interprofessional education: effects on professional practice and health care outcomes. Cochrane Database of Systematic Reviews 2008, Issue 1.

Doi:10.1002/14651858.CD002213.pub2

Schön, D., 1987. Educating the Reflective Practitioner. Jossey-Bass Publishers, San Fransisco, CA

Solvoll, B., Heggen, K.M., 2010. Teaching and learning care--exploring nursing students’ clinical practice. Nurse Education Today 30 (1), 73-77. doi:10.1016/j.nedt.2009.06.003.

Thistlethwaite, J., 2012. Interprofessional education: a review of context, learning and the research agenda. Medical Education 46 (1), 58-70. doi:10.1111/j.13652923.2011.04143.x. 